\title{
Differentiation of an autonomic response through operant reinforcement'
}

\author{
David Shapiro, Andrew B. Crider and Bernard Tursky \\ HARVARD MEDICAL SCHOOL, MASSACHUSETTS MENTAL HEALTH CENTER
}

\begin{abstract}
Making reinforcement contingent upon the emission of a skin potential response maintains a stable rate of responding in contrast to a declining rate in a non-contingently reinforced control group. The effect is independent of changes in related response systems.
\end{abstract}

Attempts to condition visceral responses with operant techniques have produced varying results. Negative findings (Skinner, 1938, p. 112; Mowrer, 1938; Mandler et al., 1962) are consistent with two factor learning theories which limit autonomic conditioning to classical techniques. Recent studies suggest that autonomic responses can be modified with operant techniques (Shearn, 1962; Lisina, 1961; Fowler \& Kimmel, 1962; Kimmel \& Kimmel, 1963). The extent to which such conditioning occurs independently of concomitant or mediating changes in other autonomic and somatic functions has not been systematically investigated.

This study attempted to condition a discrete autonomic response with operant techniques while monitoring the activity of related response systems. A spontaneous change of short duration in skin potential was selected as the response to be conditioned. Skin potential and heart rate levels were measured to determine the effect of such conditioning procedures on the basal activity of these autonomic variables. Respiration records were taken as a check on the possible mediating influence of irregularities or changes in rate of breathing.

Skin potential responses were recorded from electrodes placed on an active sweating area on the thenar eminence of the right palm and an inactive area on the dorsal aspect of the right forearm. A response was defined as any change of $0.5 \mathrm{mV}$ or greater as recorded with an $\mathrm{R}-\mathrm{C}$ coupled amplifier having an input time constant of $1 \mathrm{sec}$.

Skin potential level was recorded from the same electrodes by means of a DC coupled amplifier at a reduced gain to study gradual change over time. Similar$1 y$, a cardiotachometer was used to measure continuous changes in heart rate from standard electrocardiograph electrodes placed bilaterally on the lower chest. Respiration cycle was recorded with a strain gage fixed around the waist. These measures were recorded on an Offner Type $\mathrm{R}$ dynagraph.

The subjects were seated in a lounge chair in a soundproofed, temperature-controlled room. They were told that the purpose of the experiment was to study the effectiveness of various devices for measuring thought processes and were asked to think actively about emo- tional experiences. They were also instructed that each time the recording apparatus detected their emotional thinking they would hear a tone and thereby earn five cents.

Eighteen student nurses were divided into experimental and control groups by roughly matching each experimental subject with a control on the basis of the number of skin responses emitted during an initial 5-min. resting period. This was followed immediately by a 30-min. period during which the experimental subjects were reinforced with a $70-\mathrm{db}$ tone each time a response occurred. Since the tone in itself generally evoked skin potential activity, no response occurring within $10 \mathrm{sec}$. of a tone was reinforced. Each control subject reeeived the same number of tones as her experimental match but at points of no skin response activity and not less
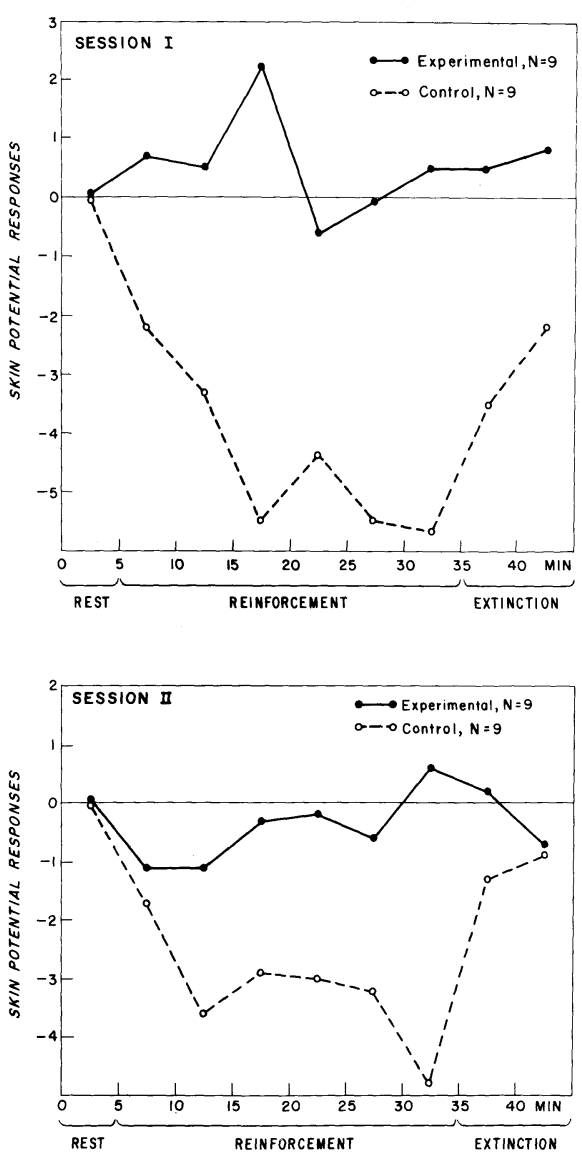

Fig. 1. Mean skin potential responses per 5-min. interval adjusted for resting period responses. 

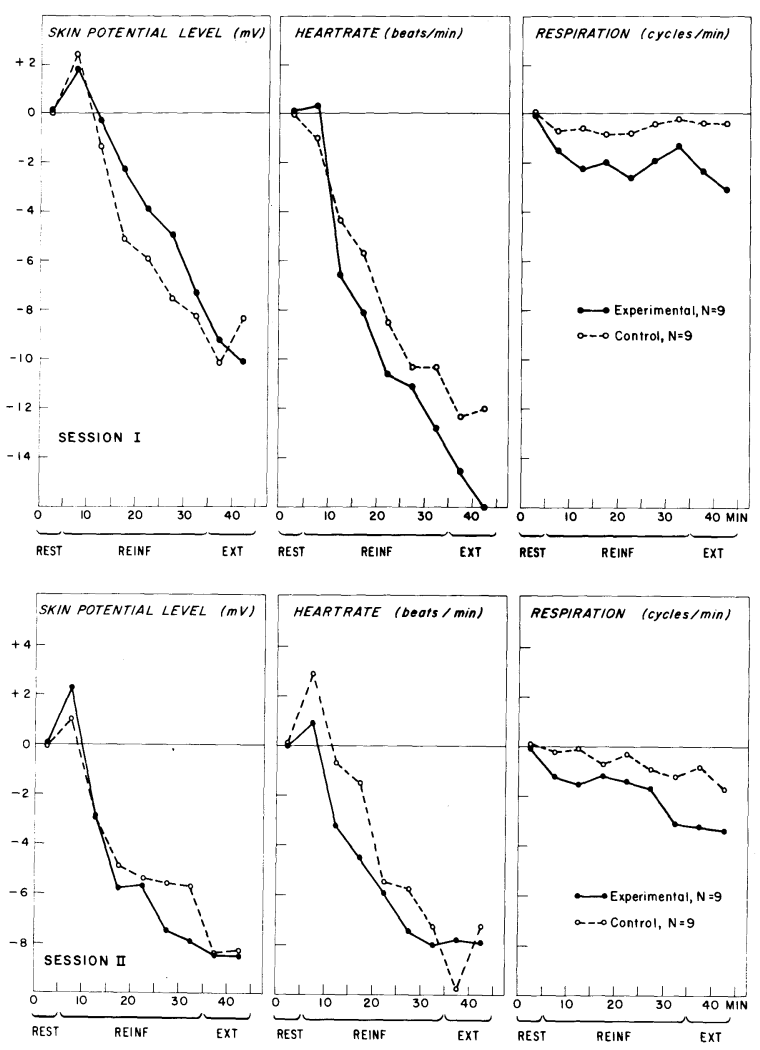

Fig. 2. Mean skin potential level, heart rate, and respiration per 5-min. interval adjusted for resting period levels.

than $10 \mathrm{sec}$. following an emitted response. The reinforcement period was followed by a $10-\mathrm{min}$. extinction period during which no tones were sounded.

The experiment was repeated in exactly the same manner for each subject after an interval of several days.

The results for both sessions were analyzed in terms of the number of skin responses spontaneously emitted in each 5-min. interval of reinforcement and extinction, equated for baseline by subtracting out the number of resting period responses (Fig. 1). During each session the experimental group maintained a stable rate of response, while the control group declined over time. Although the effect became less pronounced, the results of the second session parallel the first. For each session a group by time-interval analysis of variance for correlated observations was carried out with the reinforcement period data. A significant group by time-interval interaction for both session I $(\mathrm{P}<.001)$ and session II $(\mathrm{P}<.05)$ confirms differential responsiveness over time. There was in addition a significant overall difference between groups in session I $(P<.025)$. During extinction there was a marked increase in rate of response in the control group with no change apparent among the experimental subjects. The extinction data suggest that skin potential responses occurred as a component of an orienting reaction to the absence of tones in the final period. While this is apparent in the control group it is not seen among the experimental subjects who wereal- ready responding at a high level.

The above results are in complete accord with those reported by Fowler \& Kimmel (1962) and Kimmel \& Kimmel (1963).

Skin potential level and cardiotachometer records were sampled every $20 \mathrm{sec}$. and analyzed in terms of 5-min. time intervals adjusted for the resting period activity. Respiration records were analyzed by counting the number of inspiration-expiration cycles per min. during each interval, also adjusted (Fig. 2). No resting, reinforcement, or extinction period differences in any of these variables were found during either session; both groups showed similar trends over time. There were slightly more skin responses associated with breathing irregularities in the experimental than in the control group. When all such responses are discarded, the overall group effect of session I and the interaction effect of session II remain significant $(\mathrm{P}<.025$ and $\mathrm{P}<.05$ respectively).

All subjects were interviewed after each session. When tape recordings of the interviews were rated blindly along a 5-point scale for the subjects' perceived association between emotional thoughts and the occurrence of a tone, experimental and control group subjects were alike in finding only a moderate relationship between the two events. The control group did not report becoming less involved in the thinking task than did the experimental subjects.

Our results indicate that operant reinforcement facilitates skin response activity independently of observable changes in respiration pattern, skin potential and heart rate levels, and ideation. While we did not note any apparent differences in gross movement between the two groups, more systematic investigation of the.skeletal muscle components of such conditioning would be of value. It seems unlikely, however, that muscular activity would affect one response system independently of the others measured in this study. Operant reinforcement provides a technique for investigating the extent to which an autonomic response can be differentiated from other autonomic and somatic behavior.

\section{References}

FOWLER, R. L., \& KIMMEL, H. D. Operant conditioning of the GSR. J. exp. Psychol., 1962, 63, 563-567.

KIMMEL, ELLEN, \& KIMMEL, H. D. A replication of operant conditioning of the GSR. J. exp. Psychol., 1963, 65, 212-213.

LISINA, M. I. In G. Razran. The observable unconscious and the inferable conscious in current Soviet psycho-physiology: interoceptive conditioning, semantic conditioning, and the orienting reflex. Psychol. Rev., 1961, 68, 81-148.

MANDLER, G., PREVEN, D. W., \& KUHLMAN, C. K. Effects of operant reinforcement on the GSR. J. exp. Anal. Beh., 1962, 5, 317-321. MOWRER, O. H. Preparatory set (expectancy): a determinant in motivation and learning. Psychol. Rev., 1938, 45, 62-91.

SHEARN, D. W. Operant conditioning of heart rate. Science, 1962, $137,530-531$.

SKINNER, B. F. Behavior of organisms. New York: Appleton-CenturyCrofts, 1938.

\section{Note}

1. Supported by Research Career Development Award K3-MH-20, 476-01, NIMH; ONR Contract Nonr-1866(43), Group Psychology Branch; and Mental Health Research Training Program, NIMH. Dr. Eric Kandel offerèd many helpful suggestions during the preparation of this report. 